\title{
Comparative Effectiveness of Generic and Brand-Name Statins on Patient Outcomes
}

\section{A Cohort Study} Joshua J. Gagne, PharmD, ScD; Niteesh K. Choudhry, MD, PhD; Aaron S. Kesselheim, MD, JD, MPH; Jennifer M. Polinski, ScD, MPH;
David Hutchins, MBA, MHSA; Olga S. Matlin, PhD; Troyen A. Brennan, MD; Jerry Avorn, MD; and William H. Shrank, MD, MSHS

Background: Statins are effective in preventing cardiovascular events, but patients do not fully adhere to them.

Objective: To determine whether patients are more adherent to generic statins versus brand-name statins (lovastatin, pravastatin, or simvastatin) and whether greater adherence improves health outcomes.

Design: Observational, propensity score-matched, new-user cohort study.

Setting: Linked electronic data from medical and pharmacy claims.

Participants: Medicare beneficiaries aged 65 years or older with prescription drug coverage between 2006 and 2008.

Intervention: Initiation of a generic or brand-name statin.

Measurements: Adherence to statin therapy (measured as the proportion of days covered [PDC] up to 1 year) and a composite outcome comprising hospitalization for an acute coronary syndrome or stroke and all-cause mortality. Hazard ratios (HRs) and absolute rate differences were estimated.
Results: A total of 90111 patients who initiated a statin during the study was identified; 83731 (93\%) initiated a generic drug, and $6380(7 \%)$ initiated a brand-name drug. The mean age of patients was 75.6 years, and most $(61 \%)$ were female. The average PDC was $77 \%$ for patients in the generic group and $71 \%$ for those in the brand-name group $(P<0.001)$. An $8 \%$ reduction in the rate of the clinical outcome was observed among patients in the generic group versus those in the brand-name group $(\mathrm{HR}, 0.92[95 \% \mathrm{Cl}$, 0.86 to 0.99$]$ ). The absolute difference was -1.53 events per 100 person-years $(\mathrm{Cl},-2.69$ to -0.19 events per 100 person-years).

Limitation: Results may not be generalizable to other populations with different incomes or drug benefit structures.

Conclusion: Compared with those initiating brand-name statins, patients initiating generic statins were more likely to adhere and had a lower rate of a composite clinical outcome.

Primary Funding Source: Teva Pharmaceuticals.

Ann Intern Med. 2014;161:400-407. doi:10.7326/M13-2942

www.annals.org For author affiliations, see end of text.
Ctatins are the most frequently prescribed drugs in the United States (1) and are effective in reducing lowdensity lipoprotein (LDL) cholesterol levels and cardiovascular events (2-4). Randomized, controlled trials have found that statins reduce the relative risk for major vascular events by $21 \%$ for each $1.0-\mathrm{mmol} / \mathrm{L}(39-\mathrm{mg} / \mathrm{dL})$ reduction in LDL cholesterol level in patients at low risk for vascular disease (3). Patients assigned to statin therapy in trials tended to achieve reductions in LDL cholesterol level of $1.8 \mathrm{mmol} / \mathrm{L}$ (70 $\mathrm{mg} / \mathrm{dL})$ with doses used regularly in practice (2). However, a large body of evidence suggests that, in routine practice, patients do not fully adhere to statins and therefore may not receive their full benefit $(5,6)$. Approximately half of patients in ambulatory care settings discontinue statin therapy within 1 year of initiation $(6-8)$.

Medication nonadherence is a complex multifactorial process (9). Among its many determinants, drug cost may be one of the most easily modifiable (10). Reducing patient spending for prescription drugs can improve adherence $(11,12)$ and, in some cases, clinical outcomes (13). Ge-

See also:

Editorial comment. . . . . . . . . . . . . . . . . . . . . 447

Summary for Patients. . . . . . . . . . . . . . . . . . . I-30 neric drugs have been shown in small, short, randomized trials $(14,15)$ to be clinically equivalent to their brandname counterparts, as required for approval by the U.S. Food and Drug Administration (FDA). They are usually less expensive than brand-name products and have been associated with better adherence (12). However, no study has investigated whether use of generic versus brand-name statins also leads to improved health outcomes (16).

We sought to determine whether patients in a large cohort of Medicare beneficiaries were more adherent to therapy after initiating a generic statin versus a brand-name statin and whether this resulted in differences in health outcomes.

\section{Methods}

The study was designed by the authors and approved by the Institutional Review Board at Brigham and Women's Hospital.

\section{Study Cohort}

The study cohort comprised Medicare beneficiaries (aged $\geq 65$ years) who had prescription drug coverage through either a stand-alone Medicare Part D plan or a retiree drug plan administered by CVS Caremark, a large national pharmacy benefits manager. For each patient, we linked claims for filled prescriptions to diagnostic, health 
care utilization, and demographic data from Medicare Parts A and B files and enrollment files.

The cohort included patients who initiated a statin (lovastatin, pravastatin, or simvastatin) between 2006 and 2008 and had continuous Medicare and CVS Caremark eligibility in the 6 months before initiation. We restricted the cohort to patients initiating these drugs because they were the only statins for which generic versions were available in the United States during the study. Initiation was defined as a new (index) prescription for a study drug with no prescription for any single statin or statin combination product in the preceding 180 days. To maximize the generalizability of this comparative effectiveness study, we did not impose any other exclusion criteria.

We classified patients as exposed to a generic or brandname statin on the basis of the National Drug Code associated with the index prescription claim. We used the FDA's National Drug Code Directory (17) to determine the manufacturer of each drug and the FDA's Approved Drug Products with Therapeutic Equivalence Evaluations publication (18) to determine whether each manufacturer's products were approved via a new drug application (brandname) or abbreviated new drug application (generic).

\section{Outcomes and Follow-up}

The primary outcomes were adherence to the index statin and a composite cardiovascular outcome. Adherence was measured as the proportion of days covered (PDC) by the index statin up to 1 year after the index prescription date. The PDC is calculated by dividing the number of days of medication supplied by the number of days in a given interval (19). For each patient, the denominator interval began on the index date and ended at death, hospitalization, prescription for any other lipid-lowering drug (for example, a different statin or another lipid-lowering agent, such as a fibrate or bile acid sequestrant, although switches between brand-name and generic versions of the index statin were allowed), the end of the study (31 December 2008), or 365 days after the index prescription date, whichever occurred first. The numerator was the sum of the number of days in the interval for which medication was available based on the days supplied by each prescription.

The primary clinical outcome comprised hospitalization for an acute coronary syndrome or stroke and all-cause mortality. We also examined each of these outcomes separately. We used a validated claims-based definition for each outcome, with positive predictive values ranging from $86 \%$ to $96 \%(20-22)$. In the primary analysis, we followed patients from the day after index drug initiation until an occurrence of an event of interest, the end of the study (31 December 2008), or 365 days after initiation, whichever came first.

\section{Covariates}

We measured potential confounders in the 180-day baseline period preceding each patient's index date. Demo-

\section{Context}

Some patients do not adhere to their prescribed statins and thus do not fully benefit from the decreases in blood lipid levels that these medications provide.

\section{Contribution}

This study found that, compared with those who initiated a brand-name statin, patients who initiated a generic statin had better adherence and fewer occurrences of a composite outcome that included death from any cause plus hospitalization for an acute coronary syndrome or stroke.

\section{Caution}

All patients were Medicare beneficiaries aged 65 years or older with prescription drug coverage.

\section{Implication}

The lower cost of generic statins allowed patients to adhere to the medication better.

-The Editors

graphic variables included age, sex, and race. Health service utilization variables included the number of unique drugs dispensed, number of hospitalizations, number of cardiovascular diagnoses, number of days in the hospital, number of physician office visits, and number of physician office visits with cardiovascular diagnoses. In addition to a comorbidity score that captured patients' general health status (23), we determined whether patients had health care encounters with diagnoses for specific cardiovascular conditions (such as atrial fibrillation, congestive heart failure, or peripheral vascular disease) and other disorders (such as chronic obstructive pulmonary disease, diabetes, musculoskeletal conditions, and endocrine disease). Furthermore, we determined whether patients initiated statin treatment for primary or secondary prevention, with the latter defined as having been hospitalized for an acute coronary syndrome in the baseline period. We also measured use of preventive services, including screening mammography and vaccinations, to account for healthy-user effects $(24$, 25 ) and ascertained proxies of frailty, such as use of supplemental oxygen, to account for the propensity to stop preventive medications in patients who are very ill (26). Finally, we geocoded patients' street addresses and linked them to U.S. census data at the block group level, which is the lowest level for which data are publicly available. We identified the unemployment rate and the median household income in each patient's census block group as proxies for socioeconomic status (SES).

\section{Statistical Analysis}

We used propensity score matching (27) to mitigate confounding due to different characteristics between the brand-name and generic groups. The propensity score,

\footnotetext{
16 September $2014 \mid$ Annals of Internal Medicine $\mid$ Volume 161 • Number $6 \mid \mathbf{4 0 1}$
} 
Original RESEARCH Comparative Effectiveness of Generic and Brand-Name Statins

Table 1. Baseline Characteristics of Generic and Brand-Name Statin Recipients

Characteristic

Mean age (SD), $y$

Female, $n(\%)$

Race, $n(\%)$

White

African American

Other/missing

Median unemployment rate in census block group (IQR), \%

Median household income in census block group (IQR), U.S. \$

Mean health service utilization (SD)

Cardiovascular diagnoses, $n$

Hospitalizations, $n$

Total length of hospital stay, $d$

Physician visits, $n$

Physician visits with cardiovascular diagnosis, $n$

Unique medications, $n$

Mean comorbidity score (SD)

Diagnosis and procedure history, $n(\%)$

Secondary prevention

Cardiovascular symptoms

Acute coronary syndrome

Coronary revascularization

Coronary artery bypass grafting (old)

Coronary artery bypass grafting (new)

Angina

Atrial fibrillation

Chest pain

Congestive heart failure

Hospitalization for congestive heart failure

Conduction disorder

Coronary atherosclerosis

Disorder of lipid metabolism

Hypertension

Ischemic heart disease

Myocardial infarction

Palpitations

Peripheral vascular disease

Postsurgical aortocoronary bypass

Stroke (excluding transient ischemic attack)

Transient ischemic attack

Chronic obstructive pulmonary disease

Alzheimer disease or other dementia

Depression

Cancer

Hyperthyroidism

Diabetes mellitus

Kidney disease (excluding end-stage renal disease)

End-stage renal disease

Dialysis

Urinary tract infection

Osteoporosis

Rheumatoid arthritis

History of falls

Hip fracture

Outpatient preventive service use and indicators of frailty, $n(\%)$

Bone mineral density test

Electrocardiography

Lipid blood test

Use of supplemental oxygen

Any preventive caret
Total Eligible Cohort

\begin{tabular}{cc}
\hline Generic $(n=83$ 731) & Brand-Name $(n=6380)$ \\
$75.6(7.1)$ & $75.1(6.7)$ \\
$51690(61.7)$ & $3442(54.0)$ \\
& \\
$40150(48.0)$ & $4228(66.3)$ \\
$5590(6.7)$ & $391(6.1)$ \\
$37991(45.4)$ & $1761(27.6)$ \\
$10.0(7.0-14.2)$ & $9.1(6.4-12.5)$
\end{tabular}

51604.5 (38 070.0-69 894.0) $\quad 55807.5$ (42 344.0-75 350.0)

$\begin{array}{ll}4.8(6.2) & 4.4(5.7) \\ 0.3(0.8) & 0.3(0.7) \\ 2.2(7.4) & 2.1(6.5) \\ 4.1(4.0) & 4.5(4.1) \\ 1.9(2.3) & 2.0(2.4) \\ 8.0(4.6) & 8.3(4.7) \\ 1.7(1.9) & 1.5(1.9)\end{array}$

$4.4(5.4)$

$0.3(0.7)$

$2.0(7.5)$

$4.6(4.6)$

$2.0(2.4)$

$8.2(4.6)$

$1.5(1.8)$

$10570(12.6)$

$8579(10.3)$

$8701(10.4)$

3098 (3.7)

$3504(4.2)$

$850(1.0)$

$6591(7.9)$

$2479(3.0)$

17452 (20.8)

12165 (14.5)

$1467(1.8)$

$3333(4.0)$

23248 (27.8)

59601 (71.2)

62682 (74.9)

$8246(9.9)$

2902 (3.5)

$3115(3.7)$

$1671(2.0)$

3385 (4.0)

3321 (4.0)

3349 (4.0)

$4222(5.0)$

6289 (7.5)

4561 (5.5)

13151 (15.7)

1151 (1.4)

34282 (40.9)

6719 (8.0)

$1135(1.4)$

$559(0.7)$

11297 (13.5)

7995 (9.6)

$2183(2.6)$

$1006(1.2)$

$217(0.3)$

$1.5(1.9)$

$878(13.8)$

$649(10.2)$

731 (11.5)

$320(5.0)$

363 (5.7)

109 (1.7)

579 (9.1)

235 (3.7)

1271 (19.9)

790 (12.4)

107 (1.7)

282 (4.4)

2013 (31.6)

4648 (72.9)

$4532(71.0)$

721 (11.8)

246 (3.9)

258 (4.0)

129 (2.0)

348 (5.5)

205 (3.2)

238 (3.7)

272 (4.3)

264 (4.1)

267 (4.2)

$1266(19.8)$

82 (1.3)

2261 (35.4)

340 (5.3)

$66(1.0)$

$33(0.5)$

669 (10.5)

$523(8.2)$

$147(2.3)$

$62(1.0)$

$14(0.2)$

916 (14.4)

666 (10.5)

739 (11.6)

294 (4.6)

315 (4.9)

95 (1.5)

590 (9.3)

229 (3.6)

1270 (19.9)

797 (12.5)

104 (1.6)

267 (4.2)

1958 (30.7)

4684 (73.5)

4511 (70.8)

733 (11.5)

228 (3.6)

278 (4.4)

$115(1.8)$

298 (4.7)

213 (3.3)

225 (3.5)

278 (4.4)

271 (4.3)

239 (3.8)

1270 (19.9)

90 (1.4)

2259 (35.4)

340 (5.3)

$58(0.9)$

$29(0.5)$

$667(10.5)$

$530(8.3)$

$142(2.2)$

$63(1.0)$

$11(0.2)$

831 (1.0)

$284(4.5)$

262 (4.1)

2471 (38.8)

2894 (45.4)

$21(0.3)$

$2833(44.4)$

$23(0.4)$

$504(0.6)$

$2722(42.7)$ 


\begin{tabular}{|c|c|c|c|}
\hline \multirow[t]{2}{*}{ Characteristic } & \multicolumn{2}{|c|}{ Total Eligible Cohort } & \multirow{2}{*}{$\begin{array}{l}\text { Generic (1:1 Matched } \\
\text { Secondary Analysis) } \\
(n=6380)^{*}\end{array}$} \\
\hline & Generic $(n=83731)$ & Brand-Name $(n=6380)$ & \\
\hline \multicolumn{4}{|l|}{ Prescription drug use, $n(\%)$} \\
\hline Proton-pump inhibitors & $20106(24.0)$ & $1591(24.9)$ & $1619(25.4)$ \\
\hline Antiarrhythmics & $3816(4.6)$ & $300(4.7)$ & $289(4.5)$ \\
\hline Anti-inflammatory drugs & 14105 (16.9) & 1065 (16.7) & $1090(17.1)$ \\
\hline Antifungals & $5107(6.1)$ & $368(5.8)$ & $538(5.6)$ \\
\hline Hormone replacement therapy & $3398(4.1)$ & $354(5.6)$ & $360(5.7)$ \\
\hline Erectile dysfunction drugs & $1121(1.3)$ & $154(2.4)$ & $157(2.5)$ \\
\hline Osteoporosis drugs & $10892(13.0)$ & $854(13.4)$ & $806(12.6)$ \\
\hline Psychoactive drugs & 26605 (31.8) & $2070(32.5)$ & $2052(32.2)$ \\
\hline
\end{tabular}

$\mathrm{IQR}=$ interquartile range.

* Shows the balance achieved by propensity score matching.

† Gynecologic examination, prophylactic vaccination, routine medical examination, or screening mammography.

which was estimated with a logistic regression model, was defined as a patient's probability of receiving a generic statin versus a brand-name statin and was conditional on measured baseline covariates. We matched generic and brand-name drug recipients by using a nearest-neighbor algorithm and within calipers of 0.05 units on the propensity score scale in the primary analysis. Because the cohort included many more generic than brand-name drug recipients, we matched each patient in the brand-name group to as many patients as possible in the generic group with similar propensity scores within the specified caliper. We matched brand-name drug recipients only to recipients of the generic version of the same product (for example, brand-name and generic simvastatin) to compare patients who had initiated molecularly identical drugs. This ensured that differences in outcome rates between treatment groups could be attributed to the generic versus brandname status rather than to differences among the 3 statins. To assess the performance of the propensity score matching process, we evaluated balance in each baseline covariate and overlap in propensity score distributions between treatment groups before and after matching.

We used Cox proportional hazards models to estimate hazard ratios (HRs) and 95\% CIs. To account for the variable ratio matching, the Cox models were stratified by matching set. We also estimated rate differences.

We performed several prespecified secondary, sensitivity, and subgroup analyses to assess the validity of our study assumptions. We altered our primary analysis by shortening (to 90 days) and lengthening (to 720 days) the maximum follow-up time, excluding events that occurred within 30 and 60 days after index drug initiation, and performing 1:1 fixed-ratio matching on the propensity score. Furthermore, outcome event rates were compared between recipients of the generic and brand-name versions of each drug separately. The primary analysis was also repeated separately for primary prevention and secondary prevention patients. We conducted an "on treatment" analysis in which we censored patients when they discon- tinued statin therapy, defined as a gap of more than 30 days without filling a statin prescription beyond the number of days supplied by the last prescription or switching to another lipid-lowering treatment. Such an analysis would mitigate between-group differences in outcome rates that may be attributable to differences in treatment persistence because patients would not contribute unexposed persontime after discontinuing their index statin. We conducted post hoc sensitivity analyses in which we asymmetrically trimmed patients in the tails of the propensity score distributions by using the approach described by Stürmer and colleagues (28) and used smaller matching calipers of $0.025,0.01$, and 0.001 . In the trimmed analysis, we set cut points corresponding to the 2.5 th propensity score percentile among patients in the generic group and 97.5 th propensity score percentile among those in the brand-name group. Finally, to further assess the robustness of our results, we conducted a post hoc analysis using incidence of cancer as a negative control outcome (the Appendix Table, available at www.annals.org, shows specific cancer types and corresponding diagnosis codes). We restricted this analysis to patients with no evidence of cancer in the baseline period and followed them until they received a cancer diagnosis, lost enrollment eligibility, or reached the end of the study, whichever occurred first. We hypothesized that different cancer rates in the generic and brand-name groups would suggest the presence of bias, such as from unadjusted confounding or differential surveillance during follow-up.

\section{Role of the Funding Source}

This study was supported by an unrestricted research grant from Teva Pharmaceuticals. The sponsor had no role in the design or conduct of the study; collection, management, analysis, or interpretation of the data; or preparation of the manuscript. The sponsor was given the opportunity to review the manuscript but had no role in its approval or the decision to submit it for publication.

16 September $2014 \mid$ Annals of Internal Medicine $\mid$ Volume 161 • Number $6 \mid \mathbf{4 0 3}$ 


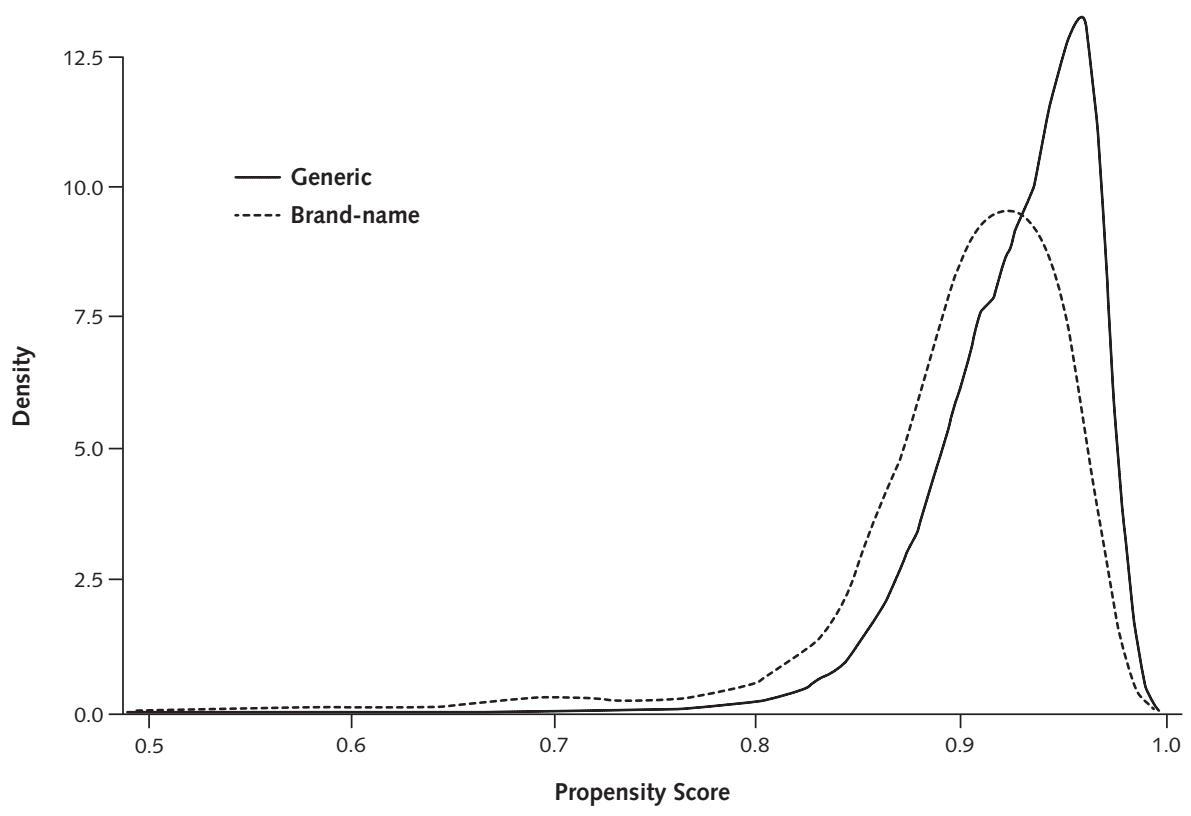

\section{RESULTS}

We identified 90111 patients who met the study eligibility criteria and initiated a statin during the study (Table 1). Of these, 83731 (93\%) initiated a generic statin. Most patients (62 122 [69\%]) initiated simvastatin (57 493 in the generic group and 4629 in the brandname group), whereas 16024 (18\%) initiated pravastatin (14 304 in the generic group and 1720 in the brand-name group) and 11965 (13\%) initiated lovastatin (11 934 in the generic group and 31 in the brand-name group). The mean age of patients in the cohort was 75.6 years, generic drug recipients were more likely to be female $(62 \%$ vs. $54 \%$ ), and brand-name drug recipients were more commonly white (66\% vs. $48 \%)$. Baseline health service utilization and clinical characteristics were similar in both groups, but patients in the generic group lived in census block groups with higher unemployment rates and lower median household incomes. We found matches for all pa-

Table 2. Hazard Ratios for Outcomes Among Generic Versus Brand-Name Statin Recipients

\begin{tabular}{lll} 
Outcome & \multicolumn{2}{c}{ Hazard Ratio $(95 \% \mathrm{Cl})$} \\
\cline { 2 - 3 } & $\begin{array}{l}\text { Unmatched } \\
\text { (Crude) }\end{array}$ & $\begin{array}{l}\text { Propensity } \\
\text { Score-Matched }\end{array}$ \\
\hline $\begin{array}{l}\text { Composite end point } \\
\text { Hospitalization for an } \\
\begin{array}{l}\text { acute coronary } \\
\text { syndrome }\end{array}\end{array}$ & $0.94(0.88-1.00)$ & $0.92(0.86-0.99)$ \\
\hline $\begin{array}{l}\text { Hospitalization for stroke } \\
\text { Death from any cause }\end{array}$ & $0.92(0.86-0.98)$ & $0.92(0.85-0.99)$ \\
\hline
\end{tabular}

$404 \mid 16$ September 2014 $\mid$ Annals of Internal Medicine $\mid$ Volume 161 • Number 6 tients because there was complete overlap in propensity score distributions between groups (Figure 1). To demonstrate covariate balance achieved by propensity score matching, Table 1 also presents the baseline characteristics for the 6380 generic drug recipients who were matched in a 1:1 ratio to brand-name drug recipients in the secondary analysis.

For the primary adherence outcome, the average PDC was $77 \%$ for patients in the generic group and $71 \%$ for those in the brand-name group $(P<0.001)$. Among 55496 total person-years of follow-up, 10582 patients $(12 \%)$ had at least 1 clinical outcome of interest, which corresponded to a crude incidence rate for the composite end point of 19.1 events per 100 person-years. After adjustment for confounding, we observed an $8 \%$ reduction in the rate of the primary composite outcome among generic drug recipients compared with brand-name drug recipients (HR, 0.92 [95\% CI, 0.86 to 0.99]) (Table 2). The absolute rate difference in the primary composite end point was -1.53 events per 100 person-years (CI, -2.69 to -0.19 events per 100 person-years). The HRs for each of the component outcomes are listed in Table 2.

The direction and magnitude of secondary, sensitivity, and subgroup analyses were generally consistent with the primary findings except for the lovastatin analysis, in which few patients were exposed to the brand-name version, as reflected by the wide CI (Figure 2). Censoring patients at the time of discontinuation, and thus removing the potential mediating effect of medication persistence, resulted in an HR of 1.00 (CI, 0.91 to 1.09 ), suggesting that adherence to therapy was the factor responsible for the primary 
findings in this study. In the analysis that used cancer as a negative control outcome, we did not find any difference in cancer incidence rates between the groups (HR, 1.01 [CI, 0.85 to 1.20$]$ ).

\section{Discussion}

In a head-to-head comparison, we found that patients initiating generic statins were more likely than those initiating brand-name statins to adhere to their prescribed treatment and had an $8 \%$ lower rate of a composite end point of cardiovascular events and death. Generic drug use has been widely recognized to reduce patient out-of-pocket costs and payer spending. Most persons in the United States are enrolled in prescription drug insurance programs with tiered benefits that require higher copayments for brand-name prescriptions than bioequivalent generic versions (29). Among patients in our study, the mean copayment for the index statin prescription was $\$ 10$ for generic drug recipients and $\$ 48$ for brand-name drug recipients. Our finding that adherence is greater with generic statins than with brand-name statins is therefore not surprising and is consistent with other studies that have shown a direct relation between higher copayments and lower adherence $(12,30,31)$. However, to our knowledge, our study is the first to assess clinical effects of the decision to initiate a brand-name or generic medication.

Our finding of an $8 \%$ reduction in the rate of the composite outcome among generic versus brand-name statin recipients is commensurate with the expected effect based on the observed difference in adherence. Randomized trials have found that statin doses that are regularly used in clinical practice result in reductions in LDL cholesterol level of $1.8 \mathrm{mmol} / \mathrm{L}$ (70 mg/dL) (2), which translates to an estimated 38\% expected reduction in major vascular events. Assuming 90\% adherence to statin therapy in the randomized trials $(32,33)$, we would expect a $42 \%$ reduction in major vascular events with perfect adherence. Given the observed PDCs of $77 \%$ for generic statin recipients and $71 \%$ for brand-name statin recipients, we would therefore expect associated reductions in vascular events of $32.3 \%$ and $29.8 \%$, respectively, or a $7.7 \%$ relative reduction for generic statin recipients compared with brandname statin recipients. Censoring patient follow-up at index drug discontinuation removed the observed protective effect of generic statin initiation, which supports the hypothesis that the improved clinical outcomes are mediated by a longer average duration of use of generic versus brandname statins.

To the extent possible, we designed our observational study like a randomized trial. We focused on new users of the index drugs and followed them by using the intentionto-treat principle. Although we were not able to randomly assign patients to generic or brand-name statins, we used propensity scores to balance measured baseline characteristics between the groups. Unlike many randomized trials, which often focus on surrogate end points, such as decrease in LDL cholesterol level, our study focused on the clinical outcomes of hospitalization or death.

Our study has limitations. Nonrandomized studies are susceptible to bias due to confounding. Although we used propensity score methods to adjust for baseline differences in a large number of patient characteristics and compared patients initiating a generic statin with those initiating brand-name versions of the same drug, generic and brandname drug recipients may have differed in ways that we were not able to measure. Previous studies have reported mixed findings about the role of SES in generic versus brand-name drug use (34-36). Before conducting propen-

\section{Figure 2. Forest plot of secondary and sensitivity analyses.}

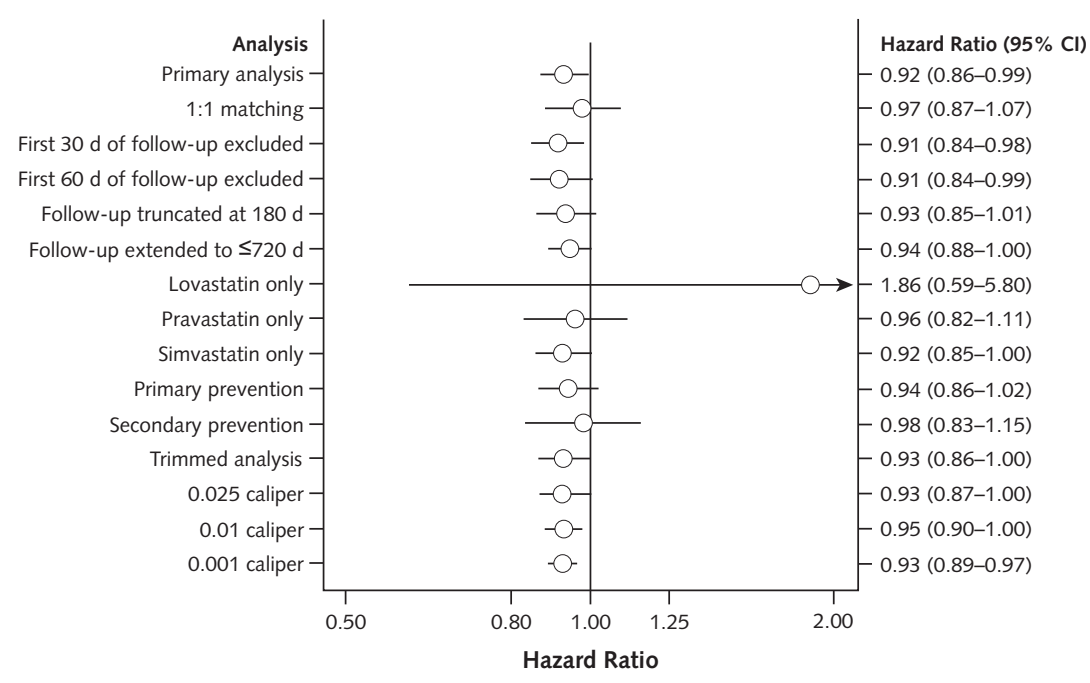


sity score matching, we found that generic statin recipients in our cohort lived in census block groups with slightly higher unemployment rates and lower household incomes. Because low SES is generally associated with worse health outcomes, we would expect any residual confounding by unmeasured aspects of SES to cause an upward bias in favor of brand-name medications. As the propensity scorematched cohort shows, these proxies of SES were wellbalanced in the analysis and, as would be expected, the adjusted estimates were generally lower than the unadjusted ones. However, these variables represent area-level, rather than individual-level, markers of SES and residual confounding may remain, implying that our results may be conservative. We used cancer as a negative control outcome (37) to further evaluate whether our findings might be due to unadjusted differences in characteristics between generic and brand-name statin recipients. Some observational studies have found an inverse association between statin use and cancer (38), but this has not been found in randomized, controlled trials (39) and other well-controlled observational studies $(40,41)$. The finding of no difference supports the robustness of our primary results. Furthermore, the results of the primary analysis were driven largely by acute coronary syndromes, which is consistent with the pharmacology of statins (2).

We were not able to determine who decided whether patients initiated a generic statin versus a brand-name statin. Many states require pharmacists to dispense a generic version of a product, when available, unless the prescriber or patient explicitly requests otherwise. Our study was limited to 3 statins for which generic versions were available at the time. Generic versions of atorvastatin and fluvastatin have become available in the United States since the end of our study, which may further increase generic statin utilization. However, many patients still receive brand-name drugs when a bioequivalent generic version is available (42), a new brand-name statin (pitavastatin) has been approved since the study ended (43), and rosuvastatin remains a top-selling product in the United States $(\$ 4.4$ billion in sales in 2011) (1). Although all generic drugs are held to the same approval standards, our results, which are based on what are generally considered to be low-intensity statins, may not apply to the higher-intensity statins atorvastatin and rosuvastatin. Furthermore, use of pharmacy claims data did not allow us to discriminate between differences in patterns of adherence that can occur with each prescription, such as when patients fully adhere for 30 days followed by a 14-day hiatus versus when patients intermittently miss doses over the same 44-day period. We expect both patterns to limit statins' LDL cholesterol-lowering ability and subsequent cardioprotective effects, but we were not able to compare the extent to which this may occur. Also, we used an intention-to-treat approach to model the effect of the decision to initiate treatment with a generic versus brand-name product, in which we followed patients for clinical outcomes regardless of whether they discontin- ued the index statin or switched between generic and brand-name versions. Such switching could result in exposure misclassification, which would generally bias results toward the null. Finally, our study population comprised U.S. Medicare beneficiaries aged 65 years or older, and our results may not be generalizable to populations with lower cardiovascular event risk, those in which drug costs may be a less important determinant of adherence, or those in which patients pay similar amounts for generic and brandname drugs.

In conclusion, in the setting of tiered copayments in typical pharmacy benefit designs, initiating a generic versus a brand-name statin seems to be associated with lower outof-pocket costs, improved adherence to therapy, and improved clinical outcomes.

From the Division of Pharmacoepidemiology and Pharmacoeconomics, Department of Medicine, Brigham and Women's Hospital and Harvard Medical School, Boston, Massachusetts, and CVS Caremark, Woonsocket, Rhode Island.

Note: Dr. Gagne had full access to all of the data in the study and takes responsibility for the integrity of the data and the accuracy of the data analysis.

Grant Support: By Teva Pharmaceuticals (2010A057139).

Disclosures: Disclosures can be viewed at www.acponline.org/authors /icmje/ConflictOfInterestForms.do?msNum=M13-2942.

Reproducible Research Statement: Study protocol and statistical code: Available from Dr. Gagne (e-mail, jgagne1@partners.org). Data set: Not available.

Requests for Single Reprints: Joshua J. Gagne, PharmD, ScD, Division of Pharmacoepidemiology and Pharmacoeconomics, Department of Medicine, Brigham and Women's Hospital and Harvard Medical School, 1620 Tremont Street, Suite 3030, Boston, MA 02120; e-mail, jgagne1@partners.org.

Current author addresses and author contributions are available at www .annals.org.

\section{References}

1. IMS Institute for Healthcare Informatics. The Use of Medicines in the United States: Review of 2010. Parsippany, NJ: IMS Institute for Healthcare Informatics; 2011. Accessed at www.imshealth.com/deployedfiles/imshealth /Global/Content/IMS Institute/Static File/IHII_UseOfMed_report.pdf on 1 May 2014.

2. Law MR, Wald NJ, Rudnicka AR. Quantifying effect of statins on low density lipoprotein cholesterol, ischaemic heart disease, and stroke: systematic review and meta-analysis. BMJ. 2003;326:1423. [PMID: 12829554]

3. Mihaylova B, Emberson J, Blackwell L, Keech A, Simes J, Barnes EH, et al; Cholesterol Treatment Trialists' (CTT) Collaborators. The effects of lowering LDL cholesterol with statin therapy in people at low risk of vascular disease: meta-analysis of individual data from 27 randomised trials. Lancet. 2012;380: 581-90. [PMID: 22607822] doi:10.1016/S0140-6736(12)60367-5

4. Thavendiranathan P, Bagai A, Brookhart MA, Choudhry NK. Primary prevention of cardiovascular diseases with statin therapy: a meta-analysis of randomized controlled trials. Arch Intern Med. 2006;166:2307-13. [PMID: 17130382] 
5. Shroufi A, Powles JW. Adherence and chemoprevention in major cardiovascular disease: a simulation study of the benefits of additional use of statins. J Epidemiol Community Health. 2010;64:109-13. [PMID: 20056964] doi:10.1136 /jech.2009.091033

6. Benner JS, Glynn RJ, Mogun H, Neumann PJ, Weinstein MC, Avorn J. Long-term persistence in use of statin therapy in elderly patients. JAMA. 2002; 288:455-61. [PMID: 12132975]

7. Chan DC, Shrank WH, Cutler D, Jan S, Fischer MA, Liu J, et al. Patient, physician, and payment predictors of statin adherence. Med Care. 2010;48:196202. [PMID: 19890219] doi:10.1097/MLR.0b013e3181c132ad

8. Avorn J, Monette J, Lacour A, Bohn RL, Monane M, Mogun H, et al. Persistence of use of lipid-lowering medications: a cross-national study. JAMA. 1998;279:1458-62. [PMID: 9600480]

9. Choudhry NK, Winkelmayer WC. Medication adherence after myocardial infarction: a long way left to go [Editorial]. J Gen Intern Med. 2008;23:216-8. [PMID: 18183470] doi:10.1007/s11606-007-0478-8

10. Desai NR, Choudhry NK. Impediments to adherence to post myocardial infarction medications. Curr Cardiol Rep. 2013;15:322. [PMID: 23250659] doi:10.1007/s11886-012-0322-6

11. Choudhry NK, Avorn J, Glynn RJ, Antman EM, Schneeweiss S, Toscano M, et al; Post-Myocardial Infarction Free Rx Event and Economic Evaluation (MI FREEE) Trial. Full coverage for preventive medications after myocardial infarction. N Engl J Med. 2011;365:2088-97. [PMID: 22080794] doi:10.1056 /NEJMsa1107913

12. Shrank WH, Hoang T, Ettner SL, Glassman PA, Nair K, DeLapp D, et al. The implications of choice: prescribing generic or preferred pharmaceuticals improves medication adherence for chronic conditions. Arch Intern Med. 2006; 166:332-7. [PMID: 16476874]

13. Choudhry NK, Fischer MA, Avorn JL, Lee JL, Schneeweiss S, Solomon $\mathrm{DH}$, et al. The impact of reducing cardiovascular medication copayments on health spending and resource utilization. J Am Coll Cardiol. 2012;60:1817-24. [PMID: 23040581] doi:10.1016/j.jacc.2012.06.050

14. Kesselheim AS, Misono AS, Lee JL, Stedman MR, Brookhart MA, Choudhry NK, et al. Clinical equivalence of generic and brand-name drugs used in cardiovascular disease: a systematic review and meta-analysis. JAMA. 2008; 300:2514-26. [PMID: 19050195] doi:10.1001/jama.2008.758

15. Kesselheim AS, Stedman MR, Bubrick EJ, Gagne JJ, Misono AS, Lee JL, et al. Seizure outcomes following the use of generic versus brand-name antiepileptic drugs: a systematic review and meta-analysis. Drugs. 2010;70:605-21. [PMID: 20329806] doi:10.2165/10898530-000000000-00000

16. Green JB, Ross JS, Jackevicius CA, Shah ND, Krumholz HM. When choosing statin therapy: the case for generics. JAMA Intern Med. 2013;173:22932. [PMID: 23303273] doi:10.1001/jamainternmed.2013.1529

17. U.S. Food and Drug Administration. National Drug Code Directory. Silver Spring, MD: U.S. Food and Drug Administration; 2014. Accessed at www .accessdata.fda.gov/scripts/cder/ndc/default.cfm on 1 May 2014.

18. U.S. Food and Drug Administration. Orange Book: Approved Drug Products with Therapeutic Equivalence Evaluations. Silver Spring, MD: U.S. Food and Drug Administration; 2012. Accessed at www.accessdata.fda.gov/scripts /Cder/ob/default.cfm on 1 May 2014.

19. Choudhry NK, Shrank WH, Levin RL, Lee JL, Jan SA, Brookhart MA, et al. Measuring concurrent adherence to multiple related medications. Am J Manag Care. 2009;15:457-64. [PMID: 19589013]

20. Kiyota Y, Schneeweiss S, Glynn RJ, Cannuscio CC, Avorn J, Solomon DH. Accuracy of Medicare claims-based diagnosis of acute myocardial infarction: estimating positive predictive value on the basis of review of hospital records. Am Heart J. 2004;148:99-104. [PMID: 15215798]

21. Tirschwell DL, Longstreth WT Jr. Validating administrative data in stroke research. Stroke. 2002;33:2465-70. [PMID: 12364739]

22. Varas-Lorenzo C, Castellsague J, Stang MR, Tomas L, Aguado J, PerezGutthann S. Positive predictive value of ICD-9 codes 410 and 411 in the identification of cases of acute coronary syndromes in the Saskatchewan Hospital automated database. Pharmacoepidemiol Drug Saf. 2008;17:842-52. [PMID: 18498081] doi:10.1002/pds.1619

23. Gagne JJ, Glynn RJ, Avorn J, Levin R, Schneeweiss S. A combined comorbidity score predicted mortality in elderly patients better than existing scores. J Clin Epidemiol. 2011;64:749-59. [PMID: 21208778] doi:10.1016/j.jclinepi .2010 .10 .004
24. Brookhart MA, Patrick AR, Dormuth C, Avorn J, Shrank W, Cadarette SM, et al. Adherence to lipid-lowering therapy and the use of preventive health services: an investigation of the healthy user effect. Am J Epidemiol. 2007;166: 348-54. [PMID: 17504779]

25. Shrank WH, Patrick AR, Brookhart MA. Healthy user and related biases in observational studies of preventive interventions: a primer for physicians. J Gen Intern Med. 2011;26:546-50. [PMID: 21203857] doi:10.1007/s11606-010 $-1609-1$

26. Glynn RJ, Knight EL, Levin R, Avorn J. Paradoxical relations of drug treatment with mortality in older persons. Epidemiology. 2001;12:682-9. [PMID: 11679797]

27. Rosenbaum PR, Rubin DB. The central role of the propensity score in observational studies for causal effects. Biometrika. 1983;70:41-55.

28. Stürmer T, Rothman KJ, Avorn J, Glynn RJ. Treatment effects in the presence of unmeasured confounding: dealing with observations in the tails of the propensity score distribution—a simulation study. Am J Epidemiol. 2010;172: 843-54. [PMID: 20716704] doi:10.1093/aje/kwq198

29. Claxton G, Rae M, Panchal N, Damico A, Lundy J, Bostick N, et al. Employer Health Benefits 2012 Annual Survey. Menlo Park, CA: Henry J. Kaiser Family Foundation; 2012. Accessed at http://kff.org/private-insurance/report /employer-health-benefits-2012-annual-survey on 1 May 2014.

30. Taira DA, Wong KS, Frech-Tamas F, Chung RS. Copayment level and compliance with antihypertensive medication: analysis and policy implications for managed care. Am J Manag Care. 2006;12:678-83. [PMID: 17090224]

31. Goldman DP, Joyce GF, Zheng Y. Prescription drug cost sharing: associations with medication and medical utilization and spending and health. JAMA. 2007;298:61-9. [PMID: 17609491]

32. Sacks FM, Pfeffer MA, Moye LA, Rouleau JL, Rutherford JD, Cole TG, et al. The effect of pravastatin on coronary events after myocardial infarction in patients with average cholesterol levels. Cholesterol and Recurrent Events Trial investigators. N Engl J Med. 1996;335:1001-9. [PMID: 8801446]

33. Prevention of cardiovascular events and death with pravastatin in patients with coronary heart disease and a broad range of initial cholesterol levels. The Long-Term Intervention with Pravastatin in Ischaemic Disease (LIPID) Study Group. N Engl J Med. 1998;339:1349-57. [PMID: 9841303]

34. Federman AD, Halm EA, Siu AL. Use of generic cardiovascular medications by elderly Medicare beneficiaries receiving generalist or cardiologist care. Med Care. 2007;45:109-15. [PMID: 17224772]

35. Federman AD, Halm EA, Zhu C, Hochman T, Siu AL. Association of income and prescription drug coverage with generic medication use among older adults with hypertension. Am J Manag Care. 2006;12:611-8. [PMID: 17026415]

36. Shrank WH, Stedman M, Ettner SL, DeLapp D, Dirstine J, Brookhart MA, et al. Patient, physician, pharmacy, and pharmacy benefit design factors related to generic medication use. J Gen Intern Med. 2007;22:1298-304. [PMID: 17647066]

37. Lipsitch M, Tchetgen Tchetgen E, Cohen T. Negative controls: a tool for detecting confounding and bias in observational studies. Epidemiology. 2010;21: 383-8. [PMID: 20335814] doi:10.1097/EDE.0b013e3181d61eeb

38. Boudreau DM, Yu O, Johnson J. Statin use and cancer risk: a comprehensive review. Expert Opin Drug Saf. 2010;9:603-21. [PMID: 20377474] doi:10.1517 /14740331003662620

39. Dale KM, Coleman CI, Henyan NN, Kluger J, White CM. Statins and cancer risk: a meta-analysis. JAMA. 2006;295:74-80. [PMID: 16391219]

40. Setoguchi S, Glynn RJ, Avorn J, Mogun H, Schneeweiss S. Statins and the risk of lung, breast, and colorectal cancer in the elderly. Circulation. 2007;115: 27-33. [PMID: 17179016]

41. Hippisley-Cox J, Coupland C. Unintended effects of statins in men and women in England and Wales: population based cohort study using the QResearch database. BMJ. 2010;340:c2197. [PMID: 20488911] doi:10.1136 /bmj.c2197

42. Shrank WH, Liberman JN, Fischer MA, Avorn J, Kilabuk E, Chang A, et al. The consequences of requesting "dispense as written". Am J Med. 2011; 124:309-17. [PMID: 21435421] doi:10.1016/j.amjmed.2010.11.020

43. Gagne JJ, Choudhry NK. How many "me-too" drugs is too many? JAMA. 2011;305:711-2. [PMID: 21325189] doi:10.1001/jama.2011.152 
Current Author Addresses: Drs. Gagne, Choudhry, Kesselheim, Polinski, and Avorn: Division of Pharmacoepidemiology and Pharmacoeconomics, Department of Medicine, Brigham and Women's Hospital and Harvard Medical School, 1620 Tremont Street, Suite 3030, Boston, MA 02120.

Mr. Hutchins: CVS Caremark, 10001 North 92nd Street, Scottsdale, AZ 85258.

Dr. Matlin: CVS Caremark, 2211 Sanders Road, Northbrook, IL 60062. Dr. Brennan: CVS Caremark, 1 CVS Drive, Woonsocket, RI 02895. Dr. Shrank: CVS Caremark, 100 Scenic View Road, Cumberland, RI 02864.

\section{Appendix Table. Cancer Outcome Definitions}

\begin{tabular}{|ll}
\hline ICD-9-CM Code & Description \\
\hline 140.x-195.x & $\begin{array}{c}\text { Malignant neoplasm, primary, except lymphatic and } \\
\text { hematopoietic }\end{array}$ \\
\hline 196.x-198.x & Malignant neoplasm, secondary \\
\hline $199 . x$ & Malignant neoplasm, unspecified sites \\
\hline $200 . x-208 . x$ & Malignant neoplasm, lymphatic and hematopoietic \\
\hline $230 . x-234 . x$ & Carcinoma in situ \\
\hline $235 . x-238 . x$ & Neoplasms of uncertain behavior \\
\hline $239 . x$ & Neoplasms of unspecified nature \\
\hline
\end{tabular}

ICD-9-CM = International Classification of Diseases, Ninth Revision, Clinical Modification.
Author Contributions: Conception and design: J.J. Gagne, A.S. Kesselheim, D. Hutchins, T.A. Brennan, W.H. Shrank.

Analysis and interpretation of the data: J.J. Gagne, N.K. Choudhry, J.M. Polinski, D. Hutchins, J. Avorn, W.H. Shrank.

Drafting of the article: J.J. Gagne, D. Hutchins.

Critical revision of the article for important intellectual content: J.J. Gagne, N.K. Choudhry, A.S. Kesselheim, J.M. Polinski, O.S. Matlin, T.A. Brennan, J. Avorn, W.H. Shrank.

Final approval of the article: J.J. Gagne, N.K. Choudhry, A.S. Kesselheim, J.M. Polinski, D. Hutchins, O.S. Matlin, T.A. Brennan, J. Avorn, W.H. Shrank.

Provision of study materials or patients: J.J. Gagne.

Statistical expertise: J.J. Gagne, J.M. Polinski, W.H. Shrank.

Obtaining of funding: J.J. Gagne, W.H. Shrank.

Administrative, technical, or logistic support: J.J. Gagne, D. Hutchins, O.S. Matlin, T.A. Brennan, J. Avorn, W.H. Shrank.

Collection and assembly of data: J.J. Gagne, D. Hutchins. 